\title{
Para-Clinical and Immunological Evaluation in Buerger's Disease as a Suspected Autoimmune Disease: Case Series
}

\author{
Abbas Shapouri-Moghaddam ${ }^{1}$, Seyed Jalil Tavakkol Afshari ${ }^{1}$, \\ Hamid Reza Rahimi², Mohammad-Hadi Saeed Modaghegh ${ }^{3}$, \\ Mahmoud Mahmoudi ${ }^{1}$, Seyed Morteza Ehteshamfar*1
}

\begin{abstract}
Background: Autoimmunity causes the loss of normal immune homeostasis and involves the presence of autoantibodies and inflammation. Thromboangiitis obliterans or Buerger's disease (BD) refers to a type of vascular obstructive syndrome, with tobacco exposure accounting for disease formation and progression. However, the current understanding of autoimmunity is unclear in the context of $\mathrm{BD}$, and the scientific findings are not enough to support autoimmune mechanisms. This study was aimed at investigating autoimmunity factors in patients with BD.

Methods: Clinical and experimental examinations were performed on 80 patients with BD. The diagnostic work-up for autoimmunity was composed of IgM rheumatoid factor (RF), anti-nuclear antibodies (ANA), The erythrocyte sedimentation rate (ESR), anti-cyclic citrullinated peptide (CCP) antibodies, Antiphospholipid antibodies (APA), Anti-cardiolipin antibodies (ACLA), anti-double-stranded DNA (ds-DNA), and extractable nuclear antigen (ENA) profile. Immunomarkers were detected using the quantitative enzyme-linked immunosorbent assay (ELISA).

Results: Raynaud's phenomenon (84.93\%), cold sensitivity (76.25\%), and claudication $(73.75 \%)$ were the most common symptoms in the BD patients. Also, 64.29\% represented with high ANA levels and positive RF, while $42.11 \%$ were found with increased ANA and ESR levels. The ANA/RF positive BD patients had ESR> $15 \mathrm{~mm} / \mathrm{hr}$ and a high prevalence of cold sensitivity, claudication, and Raynaud's phenomenon ( $\mathrm{p}>0.05$ ).

Conclusions: There is a possibility of a non-specific autoimmune disposition among BD patients. RF and ANA could be considered for predicting disease progression.
\end{abstract}

Keywords: Antibodies, Autoimmunity, Buerger's Disease, Immune System.

\section{Introduction}

Thromboangiitis obliterans, also known as Buerger's disease, is a type of vascular obstructive syndrome that is usually associated with the use of tobacco derivatives and cigarettes $(1,2)$. The reason of this obstruction is frequent and progressive inflammation, and a blood clotting in the vessels $(1,3,4)$. The clinical signs of $\mathrm{BD}$ are intermittent pain in the fingers, and pain at the tip of the fingers and toes. This disease seems to have no definitive treatment, and the only way to prevent its rapid progression is a cessation of cigarette and tobacco products $(3,5,6)$.

Buerger's disease is included in the list of differential diagnoses of all younger patients, who are referred with lower extremity ischemia. This diagnosis is strengthened in case of some clinical manifestations, such as rest pain, wounds, and gangrene (1-3). The presence of certain factors in 
the patient's records also makes this diagnosis more probable. Compared to patients with atherosclerosis, claudication is one of the rare manifestations of BD. Ischemic pain is also observed during rest or ulceration $(3,7)$. Multi organs are typically involved in BD, with Raynaud's phenomenon and thrombophlebitis occurring in $40 \%$ of these patients $(7,8)$. During the checkup, the positive result in Allen's test is useful for distinguishing the disease from atherosclerosis (9). Lupus erythematosus, rheumatoid vasculitis, antiphospholipid antibody syndrome, and mixed connective tissue disease are among the relevant differential diagnoses of $\mathrm{BD}(10,11)$.

Despite the decreasing trend in BD in North America and Western Europe, its prevalence is on the rise in Central Asia, the Far East, and the Mediterranean $(3,5)$. So far, the leading causes of the BD have not been identified; however, smoking plays an active role in its development $(4,5)$. Interestingly, there are some pieces of evidence in the related literature about patients who had no history of smoking $(12,13)$. With this in mind, other factors may exist that affect the etiology of BD. Some studies have discovered viral and bacterial impacts, narcotics, and environmental and genetic conditions $(12,13)$.

Additionally, there are studies reporting a group of genes, which have contributions to autoimmune diseases and are widely known as the HLA complex (14-16). One of the arguable aspects of the BD etiology is autoimmunity. The probable association between the immune system and BD has been investigated to some extent in previous studies $(1,12,17,18)$.

The objective of the present study was to assess the presence of possible autoimmune phenomena in $\mathrm{BD}$ patients and the potential role of anti-nuclear antibodies (ANA)/IgM rheumatoid factor (RF) in developing the most common clinical symptoms.

\section{Materials and Methods Ethical statement}

This study was approved by the Medical Research Committee of Mashhad University of Medical Sciences (MUMS), Mashhad, Iran.

\section{Patient selection}

This was a cross-sectional study, where 91 participants were initially recruited according to a call from the Vascular and Endovascular Research Center in 2012. They were then examined based on Shionoya's clinical criteria (5, 19). Also, those patients who were reluctant to participant or share additional information about their autoimmune diseases, malignancy, viral diseases, and allergies were removed from the study. In total, 80 male patients were confirmed with a score of 4 and 5 for further assessments.

\section{Study protocol}

After sampling, informed consents were obtained from the patients. Additionally, the participant's demographic data and clinical symptoms were recorded in detail by specialists. For laboratory tests, $10 \mathrm{~mL}$ blood samples were collected to detect antibodies to IgM rheumatoid factor (RF), anti-nuclear antibodies (ANAs), anti-cyclic citrullinated peptide (CCP) antibodies, Antiphospholipid antibodies (APAs), Anti-cardiolipin antibodies (ACLAs), antidouble-stranded DNA (ds-DNA), and extractable nuclear antigen (ENA) profile.

The samples were screened for $\operatorname{IgM}$ rheumatoid factor (RF) (Euroimmun, Germany), anti-nuclear antibody (ANA) (Genesis, USA), anti-cyclic citrullinated peptide (anti-CCP) antibodies (Euroimmun, Germany), anti-phospholipid antibodies

(APA)

(Euroimmun, Germany), anti-cardiolipin antibodies (ACLA-G for IgG and ACLA-M for IgM) (Aesku.Diagnostics, Germany), antidouble strand DNA (dsDNA) antibodies (Euroimmun, Germany), and anti-extractable nuclear antigens (ENA) (Phadia AB, Sweden) using the enzyme-linked immunosorbent assay (ELISA). According to the manufacturers' instructions, RF $<15 \mathrm{IU} / \mathrm{mL}$, ANA $<1 \mathrm{IU}$, $\mathrm{CCP}<20 \mathrm{U} / \mathrm{mL}, \mathrm{APA}<20 \mathrm{SGU}$ or $20 \mathrm{SMU}$, ACLA $<40$ GPL or 40 MPL, ds-DNA $<30$ $\mathrm{IU} / \mathrm{mL}$, and ENA profile $<1 \mathrm{U}$ with corresponding ranges less than $15 \mathrm{IU} / \mathrm{mL}, 1 \mathrm{IU}$, $20 \mathrm{U} / \mathrm{mL}, 20 \mathrm{SGU}$ or $20 \mathrm{SMU}, 40 \mathrm{GPL}$ or 40 MPL, $30 \mathrm{IU} / \mathrm{mL}$, and $1 \mathrm{U}$ were considered normal. The most common ENA specifications used for measurements are anti-SS-A, anti-SS- 
B, anti-Sm, anti-nRNP, anti-Jo-1, and antiScl70 (20).

\section{Statistical Analysis}

Data were collected and fed into SPSS13 software. Descriptive statistics were presented in the form of mean, standard deviation (SD), frequency, and percentage. The data distribution was evaluated by the Kolmogorov-Smirnov test. Mann-Whitney U test was carried out to compare ESR between patients with positive or negative ANA/RF. Pearson chi-square test was used for comparing three major clinical findings between the BD groups with positive or negative ANA/RF. In case that above $20 \%$ of cells had frequencies < 5, Fisher's exact test was run for the comparison of the symptoms.

\section{Results}

Eighty male patients with BD with an average age of $42.85 \pm 8.35$ years participated in this study. All of these samples were tobacco users, of whom $83.75 \%$ smoked cigarettes, $5 \%$ used hookahs, and $6.25 \%$ reported both cigarettes and hookahs. It was also found that $78(97.5 \%)$ patients consumed opium at the same time.

\section{Clinical findings}

Table 1 shows the distribution of BD severity and symptoms. Based on the disease progress, the symptoms of the patients were classified as mild (migratory thrombophlebitis, cold sensitivity Raynaud's phenomenon, or skin discoloration), moderate (chronic ulcers, claudication, or burning pain of the feet at night), and severe (pain at rest or gangrene) (21). The moderate symptoms were the most common $(\mathrm{n}=$ $46,57.5 \%$ ) in this study. The prevalence of the severe symptoms was around twice as many as that of the mild symptoms. Among all the patients, the majority represented with Raynaud's phenomenon (84.93\%), which was followed by cold sensitivity (76.25\%) and claudication $(73.75 \%)$. Almost half of the patients had burning pain of the feet at night $(52.05 \%)$ and skin discoloration (46.25\%). Migratory thrombophlebitis was observed in only 5 $(6.25 \%)$ men.

Table 1. The clinical properties of Buerger's disease patients.

\begin{tabular}{lll}
\hline Severity of the disease & Symptoms & Frequency (\%) \\
\hline \multirow{3}{*}{ Mild $(\mathrm{n}=11)$} & Migratory thrombophlebitis & $5(6.25)$ \\
\cline { 2 - 3 } & Cold sensitivity & $61(76.25)$ \\
\cline { 2 - 3 } & Raynaud's phenomenon & $62(84.93)$ \\
\cline { 2 - 3 } Moderate $(\mathrm{n}=46)$ & Skin discoloration & $37(46.25)$ \\
\hline \multirow{2}{*}{ Severe $(\mathrm{n}=23)$} & Chronic ulcers & $29(36.25)$ \\
\cline { 2 - 3 } & Claudication & $59(73.75)$ \\
\cline { 2 - 3 } & Burning pain of the feet at night & $38(52.05)$ \\
\hline
\end{tabular}

\section{Serum level of immunologic markers}

The results of ESR and the ELISA test on serum level of antibodies are summarized in Table 2. As can be seen, there were three immunomarkers with considerably high means; the elevated level of ANA (mean: $7.32 \pm 1.17$ IU) was found in all patients. Serum IgM rheumatoid factor with a mean level of $34.42 \pm$ $4.18 \mathrm{IU} / \mathrm{mL}$ was positive in around $65 \%$ of the
BD cases. The level of ESR was estimated 21.16 $\pm 3.08 \mathrm{~mm} / \mathrm{hr}$, being within the normal range in above half of the patients. At least $90 \%$ of the subjects were detected with normal anti-CCP, ACLA, APA, and anti-dsDNA levels. The level of antibodies produced against $\mathrm{Sm}, \mathrm{nRNP}, \mathrm{SS}-\mathrm{A}$, SS-B, Scl-70, and Jo-1 antigens in the ENA profile of the patients was normal. 
Table 2. ESR and antibodies in the study patients.

\begin{tabular}{|c|c|c|c|c|}
\hline \multicolumn{2}{|c|}{ Immunomarker } & Mean (SD) & Normal level, n(\%) & Abnormal level, n(\%) \\
\hline \multicolumn{2}{|c|}{$\mathrm{ESR}(<15 \mathrm{~mm} / \mathrm{hr})$} & $21.16(3.08)$ & $44(57.89)$ & $32(42.11)$ \\
\hline \multicolumn{2}{|c|}{ Anti-CCP $(<20 \mathrm{U} / \mathrm{mL})$} & $3.15(0.99)$ & $74(98.67)$ & $1(1.33)$ \\
\hline \multirow{2}{*}{ ACLA } & ACLA-G(<40 GPL) & $11.09(1.08)$ & $78(97.50)$ & $2(2.50)$ \\
\hline & ACLA-M(<40 MPL) & $2.11(0.37)$ & $80(100)$ & $0(0)$ \\
\hline \multirow{2}{*}{ APA } & APA-G $(<20$ SGU $)$ & $4.42(1.32)$ & $77(96.25)$ & $3(3.75)$ \\
\hline & APA-M (<20 SGU) & $2.04(0.22)$ & $80(100)$ & $0(0)$ \\
\hline \multicolumn{2}{|c|}{$\operatorname{ANA}(<1 \mathrm{IU})$} & $7.32(1.17)$ & $0(0)$ & $80(100)$ \\
\hline \multicolumn{2}{|c|}{ Anti-ds-DNA $(<30 \mathrm{IU} / \mathrm{mL})$} & $10.29(1.78)$ & $68(90.67)$ & $7(9.33)$ \\
\hline \multicolumn{2}{|c|}{ RF-IgM $(<15 \mathrm{IU} / \mathrm{mL})$} & $34.42(4.18)$ & $20(35.71)$ & $36(64.29)$ \\
\hline \multirow{6}{*}{ ENA profile } & $\operatorname{Sm}(<1 \mathrm{U})$ & $0.18(.01)$ & $80(100)$ & $0(0)$ \\
\hline & $\mathrm{nRNP}(<1 \mathrm{U})$ & $0.20(0.02)$ & $80(100)$ & $0(0)$ \\
\hline & $\operatorname{SS}-\mathrm{A}(<1 \mathrm{U})$ & $0.23(0.01)$ & $80(100)$ & $0(0)$ \\
\hline & $\mathrm{SS}-\mathrm{B}(<1 \mathrm{U})$ & $0.17(0.02)$ & $80(100)$ & $0(0)$ \\
\hline & $\operatorname{Scl}-70(<1 \mathrm{U})$ & $0.17(0.02)$ & $80(100)$ & $0(0)$ \\
\hline & Jo-1 (<1 U) & $0.21(0.02)$ & $80(100)$ & $0(0)$ \\
\hline
\end{tabular}

The ANA/RF positive BD patients had an ESR level of $18.44 \pm 3.53 \mathrm{~mm} / \mathrm{hr}$, which was comparable $(\mathrm{U}=342.00, \mathrm{p}=0.758$ ) to that in ANA/RF negative patients $(19.90 \pm 7.01$ $\mathrm{mm} / \mathrm{hr}$ ). Also, cold sensitivity $(\mathrm{n}=28,50 \%$ vs. $\mathrm{n}=15$, 26.79\%; Pearson chi-square test $\mathrm{p}=$ 0.056 ), claudication $(n=24,42.86 \%$ vs. $n=17$, $30.36 \%$; Fisher's exact test $\mathrm{p}=0.120$ ), and Raynaud's phenomenon $(n=29,51.79 \%$ vs. $n=$ 15, 26.79\%; Pearson chi-square test $\mathrm{p}=0.739$ ) were more common in ANA/RF positive BD patients that their counterparts with negative ANA/RF although the difference was not statistically significant.

\section{Discussion}

The main findings of this study were that about $65 \%$ of the patients with BD developed elevated ANA titers and positive RF-IgM, while above 40\% had elevated ANA titers and ESR higher than $15 \mathrm{~mm} / \mathrm{hr}$.

Anti-nuclear antibodies (ANA) are composed of different antibodies acting against a high number of macromolecules that constitute the normal cell nucleus. The ANA positivity has been considered a hallmark of autoimmune disease however these cannot be diagnostic. Because it is sometimes shown that a healthy population could develop ANA. As long as ANA are present, the specific antibody, which makes the ANA test positive, should be determined (22).

Anti-CCP antibodies are found to be reactive with synthetic peptides consisting of the amino acid citrulline (23). According to Moore and Dalrymple, many viral infections exist with RF positivity, such as hepatitis B and C. However, the affected patients do not contain antibodies to $\alpha \mathrm{CCP}$ (24). In the present study, more than $98 \%$ of the patients were negative for Anti-CCP.

To define other specific antibodies, an ELISA profile is required. All the patients were evaluated to realize if there was any underlying APA or ACLA. The results did not show the presence of APA-M or ACLA-M in the BD cases, whereas APA-G and ACLA-G, 
respectively, occurred in only $3.75 \%$ and $2.50 \%$. As for antibodies to dsDNA and RF-IgM, seven patients indicated positive results for dsDNA, and $65 \%$ were found with RF-IgM positivity. On the other hand, no ENA profile in our study did contain antibodies to Sm, nRNP, SS-A, SS-B, Scl70, and Jo-1.

The erythrocyte sedimentation rate (ESR) is considered a non-specific marker of inflammation and rises in inflammatory conditions (25). In this research study, all patients revealed notable ESR levels. Further analyses showed that increased ESR among the ANA/RF positive BD patients was more likely to represent a chronic inflammatory state, leading to specific symptoms, such as cold

\section{References}

1. Klein-Weigel P, Volz T, Gutsche-Petrak B, Boehnlein $\mathrm{J}$, Bohlen A. Immunoadsorption in Buerger'S Disease (Thromboangiitis Obliterans): A Promising Therapeutic Option: Results of a Consecutive Patient Cohort Treated in Clinical Routine Care. Lupus Open Access. 2016;1(114):2. 2. Narváez J, García-Gómez C, Álvarez L, Santo P, Aparicio M, Pascual M, et al. Efficacy of bosentan in patients with refractory thromboangiitis obliterans (Buerger disease): A case series and review of the literature. Medicine (Baltimore). 2016;95(48):e5511.

3. Rivera-Chavarría IJ, Brenes-Gutiérrez JD. Thromboangiitis obliterans (Buerger's disease). Ann Med Surg (Lond). 2016;7:79-82.

4. Jiménez-Ruiz C, Dale L, Mochales JA, Buendía LV, de Granda Orive I, García AG. Smoking characteristics and cessation in patients with thromboangiitis obliterans. Monaldi Arch Chest Dis. 2016;65(4):217-21.

5. Igari $\mathrm{K}$, Inoue $\mathrm{Y}$, Iwai $\mathrm{T}$. The epidemiologic and clinical findings of patients with Buerger disease. Ann Vasc Surg. 2016;30:263-9.

6. Higashi Y, Azuma N, Takeishi Y, Minamino T, Kihara Y, Node K, et al. Effect of a Low-Intensity Pulsed Ultrasound Device, SX-1001, on Clinical Symptoms in Buerger Disease with Limb Ischemia. Int Heart J. 2015;56(6):632-8. sensitivity, claudication, and Raynaud's phenomenon. This observation can imply that ANA/RF positive BD patients had mild-tomoderate severity.

The main strength of the present study was the selection of all the patients from a single center. Therefore, our sample represented an almost homogeneous BD population. As for the weakness, since the Vascular and Endovascular Research Center is a tertiary referral center, a bias could exist for more severe patients.

\section{Acknowledgements}

The financial supports of Mashhad University of Medical Sciences are acknowledged. The authors indicated no conflicts of interest.

7. De JH, Florez A, Fernandez JL, Acin F. Treatment of Buerger disease (thromboangiitis obliterans) with bosentan: a case report. BMJ Case Reports. 2009;2009.

8. Decousus H, Quéré I, Presles E, Becker F, Barrellier M-T, Chanut M, et al. Superficial venous thrombosis and venous thromboembolism: a large, prospective epidemiologic study. Ann Intern Med. 2010;152(4):218-24.

9. Del Conde I, Peña C. Buerger disease (thromboangiitis obliterans). Tech Vasc Interv Radiol. 2014;17(4):234-40.

10. Vijayakumar A, Tiwari R, Kumar Prabhuswamy V. Thromboangiitis obliterans (Buerger's disease) — current practices. Int J Inflam. 2013;2013:156905.

11. Quintero OL, Rojas-Villarraga A, Mantilla RD, Anaya J-M. Autoimmune diseases in the intensive care unit. An update. Autoimmun Rev. 2013;12(3):380-95.

12. Arnson Y, Shoenfeld Y, Amital H. Effects of tobacco smoke on immunity, inflammation and autoimmunity. J Autoimmun. 2010;34(3):J258-65. 13. Smolen JS, Youngchaiyud U, Weidinger P, Kojer M, Endler AT, Mayr WR, et al. Autoimmunological aspects of thromboangiitis obliterans (Buerger's disease). Clinical immunology and immunopathology. 1978;11(2):168-177. 
14. Hassoun Z, Lacrosse M, De Ronde T. Intestinal involvement in Buerger's disease. Journal of clinical gastroenterology. 2001;32(1):85-9.

15. Sasaki S, Sakuma M, Kunihara T, Yasuda K. Distribution of arterial involvement in thromboangiitis obliterans (Buerger's disease): results of a study conducted by the Intractable Vasculitis Syndromes Research Group in Japan. Surg today. 2000;30(7):600-5.

16. Asouri M, Alinejad Rokni H, Sahraian MA, Fattahi S, Motamed N, Doosti R, et al. Association of HLA-DRA and IL2RA Polymorphisms with the Severity and Relapses Rate of Multiple Sclerosis in an Iranian Population. rbmb. 2020;9(2):129-139.

17. Kopan R, Ilagan MXG. The canonical Notch signaling pathway: unfolding the activation mechanism. Cell. 2009;137(2):216-33.

18. Shapouri-Moghaddam A, Mohammadi M, Rahimi HR, Esmaeili H, Mahmoudi M, Modaghegh M-HS, et al. The Association of HLAA, B and DRB1 with Buerger's Disease. Rep Biochem Mol Biol. 2019;8(2):153-160.
19. Dargon PT, Landry GJ. Buerger's disease. Ann Vasc Surg. 2012;26(6):871-80.

20. Malik S, Bruner GR, Williams-Weese C, Feo L, Scofield RH, Reichlin M, et al. Presence of anti-La autoantibody is associated with a lower risk of nephritis and seizures in lupus patients. Lupus. 2007;16(11):863-6.

21. Ehteshamfar SM, Afshari JT, Modaghegh MS, Mahmoudi M, Kazemzadeh GH, Kermani FS. Humoral and cellular immune response to Buerger's disease. Vascular. 2020;28(4):457-464.

22. Fritzler MJ. The antinuclear antibody test: last or lasting gasp?. Arthritis Rheum. 2011;63(1):19-22.

23. Syed RH, Gilliam BE, Moore TL. Rheumatoid factors and anticyclic citrullinated peptide antibodies in pediatric rheumatology. Curr Rheumatol Rep. 2008;10(2):156-63.

24. Moore TL, Dalrymple AM. Laboratory Studies in Autoimmune Diseases. Mo Med. 2016;113(2):118-122.

25 . Harrison M. Erythrocyte sedimentation rate and C-reactive protein. Aust Prescr. 2015;38(3):93-94. 